\title{
The effect of Massachusetts health reform on 30 day hospital readmissions: retrospective analysis of hospital episode statistics
}

\author{
(c) $(1)$ (9)
}

\author{
Karen E Lasser associate professor of medicine ${ }^{1}$, Amresh D Hanchate assistant professor of \\ medicine $^{12}$, Danny McCormick associate professor of medicine ${ }^{3}$, Meredith G Manze visiting assistant \\ professor $^{4}$, Chieh Chu data analyst ${ }^{1}$, Nancy R Kressin professor of medicine ${ }^{1}$ senior Veterans \\ Affairs health services research and development research career scientist ${ }^{2}$
}

${ }^{1}$ Section of General Internal Medicine, Boston University School of Medicine, Boston, MA 02118, USA; ${ }^{2}$ Veterans Affairs Boston Healthcare System, Boston, MA, USA; ${ }^{3}$ Harvard Medical School, Department of Medicine, Cambridge Health Alliance, Cambridge, MA, USA; ${ }^{4}$ City University of New York School of Public Health, New York, NY, USA

\begin{abstract}
Objectives To analyse changes in overall readmission rates and disparities in such rates, among patients aged 18-64 (those most likely to have been affected by reform), using all payer inpatient discharge databases (hospital episode statistics) from Massachusetts and two control states (New York and New Jersey).

Design Difference in differences analysis to identify the post-reform change, adjusted for secular changes unrelated to reform.

Setting US hospitals in Massachusetts, New York, and New Jersey.

Participants Adults aged 18-64 admitted for any cause, excluding obstetrical.

Main outcome measure Readmissions at 30 days after an index admission.

Results After adjustment for known confounders, including age, sex, comorbidity, hospital ownership, teaching hospital status, and nurse to census ratio, the odds of all cause readmission in Massachusetts was slightly increased compared with control states post-reform (odds ratio $1.02,95 \%$ confidence interval 1.01 to $1.04, \mathrm{P}<0.05$ ). Racial and ethnic disparities in all cause readmission rates did not change in Massachusetts compared with control states. In analyses limited to Massachusetts only, there were minimal overall differences in changes in readmission rates between counties with differing baseline uninsurance rates, but black people in counties with the highest uninsurance rates had decreased odds of readmission $(0.91,0.84$ to 1.00$)$ compared with black people in counties with lower uninsurance rates. Similarly, white people in counties with the highest uninsurance rates had decreased
\end{abstract}

odds of readmission $(0.96,0.94$ to 0.99$)$ compared with white people in counties with lower uninsurance rates.

Conclusions In the United States, and in Massachusetts in particular, extending health insurance coverage alone seems insufficient to improve readmission rates. Additional efforts are needed to reduce hospital readmissions and disparities in this outcome.

\section{Introduction}

Thirty day hospital readmissions are common and costly ${ }^{1}$ and because they may signal an unnecessary use of resources have been the focus of health policy interventions to reduce cost. In March 2010, President Obama signed a comprehensive health reform, the Patient Protection and Affordable Care Act, into law. The law established a program for reduction in hospital readmissions, which requires the US Centers for Medicare and Medicaid Services to reduce payments to hospitals with excess readmissions, effective for discharges beginning on 1 October 2012. ${ }^{2}$ Uninsured patients are at increased risk for readmission, ${ }^{3}$ and there are well documented racial disparities in this outcome. ${ }^{4}$ Prior studies suggest that when people have insurance, they are more likely to have a usual source of care and to utilize medical care. Receipt of such care can prevent unnecessary and costly hospital admissions..$^{5-13}$ However, it is unknown whether expanding health insurance coverage can reduce the risk of readmissions in the overall population, specifically among minority populations, or whether an insurance expansion might have differential effects related to variation in baseline 
uninsurance rates. One mechanism by which such effects might occur is that previously uninsured people who gain insurance could also gain improved access to outpatient primary and specialty care. Such access, in turn, could enable outpatient follow-up after hospital discharge, which may prevent readmission. ${ }^{14}$ Patients could also gain coverage for medications and for treatment of comorbid conditions, which could further reduce the risk of readmission. Insurance expansion might have the greatest effects on those least likely to have been insured prior to reform, including racial and ethnic minority groups, or people residing in areas with higher pre-reform uninsurance rates. ${ }^{515} 16$

Since 2006 Massachusetts has been the setting of a landmark experiment in healthcare reform. The principal aim of the reform was to achieve near universal health insurance coverage. ${ }^{17}$ The Massachusetts reform also aimed to decrease racial and ethnic disparities in both coverage and access. The expansion of coverage has been accomplished in three ways. The first approach is an individual mandate for coverage. The Massachusetts Health Care Reform Law requires most Massachusetts adults who can afford health insurance to have coverage or pay a penalty. In 2013 the penalties ranged from $\$ 240$ (£145; €174) to \$1272 per year, depending on an individual's income, age, and family size.$^{18}$ The second approach to increasing coverage was an expansion of public coverage.

This was accomplished through an extension of Medicaid (health insurance for Massachusetts residents with the lowest income), and the creation of Commonwealth Care, a publicly subsidized plan for people with incomes below 300\% of the poverty line. Prior to these changes, Massachusetts Medicaid (MassHealth) covered families with income up to $133 \%$ of the federal poverty line. ${ }^{19}$ Finally, the reform created a health insurance exchange, "the Massachusetts Health Connector," for more affordable private insurance. ${ }^{20}$ The Health Connector is a health insurance marketplace that enables those who are not eligible for public coverage to purchase insurance offered by private health plans. The Health Connector requires health insurance carriers to meet certain requirements such as participation in all Commonwealth Choice offerings and coverage of standardized benefit packages. All forms of health insurance must meet standards for "minimal creditable coverage, ${ }^{21}$ including coverage for preventive and primary care, emergency services, hospital stays, outpatient services, prescription drugs, and mental health services. The number of uninsured Massachusetts residents fell substantially after the reform was implemented. ${ }^{22}$ Among adults aged 18 to 64-the population targeted by the reform-uninsurance rates declined from $8.4 \%$ (2006) to $3.4 \%$ (2009) overall, but from $15 \%$ to $5 \%$ among black people and $20 \%$ to $13 \%$ among Hispanic people, compared with $7 \%$ to $2 \%$ among white people. ${ }^{17}{ }^{23}{ }^{24}$ Massachusetts reform also impacted the numbers of people insured through Medicaid and private insurance. In 2005, 72\% of insurance coverage in Massachusetts was private and $11 \%$ was Medicaid, ${ }^{25}$ whereas in $2011,79 \%$ of insurance coverage in Massachusetts was private and $16 \%$ was Medicaid. ${ }^{26}$ Massachusetts therefore provides a unique opportunity to evaluate whether an expansion in coverage can impact 30 day readmissions. In addition, analyzing the effects of healthcare reform in Massachusetts may provide insight into the possible effects of the Affordable Care Act as it is implemented nationwide. Modeled on the Massachusetts experience, the Affordable Care Act similarly requires that most US citizens have health insurance. ${ }^{27}$ The Federal law also expands Medicaid and enables people who do not qualify for Medicaid to purchase coverage through state based health benefit exchanges. The Affordable Care Act requires that health insurance covers a range of services similar to those covered by Massachusetts reform. ${ }^{28}$ Some details differ between the two insurance reforms, such as the extent of the Medicaid expansion and the proposed penalty for those who do not obtain coverage.

We examined readmission rates among patients aged 18-64; we did not include patients aged 65 and older since most are covered by Medicare, and hence are unlikely to have been affected by Massachusetts health reform. We sought to determine whether readmission rates changed differentially in Massachusetts compared with two control states, New York and New Jersey, which did not expand coverage during the study period. We also examined whether disparities in readmission rates changed subsequent to reform, hypothesizing that minority groups in Massachusetts might stand to benefit the most, as they are at increased risk for readmissions ${ }^{4}$ and made the most gains in terms of insurance coverage. Finally, we evaluated whether the insurance expansion had differential effects on readmissions related to geographically varying baseline uninsurance rates, within Massachusetts only since the other states had no similar reform.

\section{Methods \\ Data}

We used all payer inpatient discharge (hospital episode statistics for admitted patients) databases from Massachusetts ${ }^{29}$ and two comparison states, New York and New Jersey. We chose these states owing to their relative geographic proximity to Massachusetts and sizable minority populations. Because individual identifiers are not available in the publicly accessible state inpatient databases, which are part of the Healthcare Cost and Utilization Project sponsored by the US Agency for Health Care Quality, we obtained discharge databases, which contain such identifiers, directly from each state, to track readmissions of the same patients over time. These databases include all non-Federal short term acute care hospitals in each state; Veterans' and psychiatric hospitals are excluded. Using 2004-09 data, we examined admissions of adults to hospital for all causes with the exception of obstetrical diagnoses. We excluded obstetrical diagnoses because pregnant women were largely insured in Massachusetts both prior to and after Massachusetts health reform. ${ }^{30}$ Though we used the individual patient discharge as the unit of analysis, we refer to individual discharges as patients, as is the convention in similar studies. ${ }^{31}$ We followed individual patients from the index admission to their first 30 day readmission; we did not follow individual patients beyond that period. We excluded three groups of patients: those admitted to hospital in each state who were not state residents, those with an in-hospital death, and those transferred to another acute care facility or discharged against medical advice.

Because our data did not include individual level information on socioeconomic status such as education, occupation, or income, we used median zip code income from 2000 US census data to infer patients' socioeconomic status. We drew on 2009 survey data from the American Hospital Association to identify hospital characteristics associated with readmissions. Such characteristics include teaching hospital status, hospital size, nurse to census ratio (calculated by dividing the number of nurses on staff by the number of patient days in thousands), hospital ownership, and presence of a cardiac intensive care unit. ${ }^{32}$ To define hospital safety net status, another hospital characteristic that may be associated with readmissions, we modified a definition used by other studies ${ }^{33}$ that is based on the percentage of patients insured by Medicaid. We expanded this definition to include patients whose insurance was identified 
as "self pay," "indigent," and "hospital responsibility," because caring for the uninsured is a key mission of safety net hospitals. We calculated the percentage of patients in each hospital who fell into these coverage groups throughout the study period (in both the pre-reform and post-reform periods), and defined safety net hospitals as those hospitals in the highest quarter.

\section{Definition of pre-reform and post-reform periods}

Implementation of Massachusetts health reform began on 1 July 2006 with expansion of Medicaid to cover previously

"enrollment capped" low income populations, culminating in a penalty enforced mandate of individual insurance coverage effective 1 January 2008. ${ }^{22}$ New York embarked on incremental health reform in 2000, expanding Medicaid eligibility and making private coverage more affordable for uninsured workers on a low income..$^{19}$ New Jersey passed legislation in 2008 to create an individual mandate for children. ${ }^{34}$ Neither state's efforts achieved near universal levels of coverage, and neither included the creation of an insurance exchange or an individual mandate for adult coverage. We examined 30 day readmissions in Massachusetts and in the comparison states (New Jersey and New York) for 21 months (1 January 2008 to 30 September 2009) after this mandate (post-reform period) and contrasted it with data for the 21 months (1 September 2004 to 30 June 2006) preceding reform (pre-reform period), excluding the transition period (1 July 2006 to 31 December 2007). Since none of the comparison states enacted comprehensive insurance expansions on the scale of Massachusetts health reform during the study period, we assume that changes in their 30 day readmission rates reflect secular trends unrelated to health reform.

\section{Outcomes}

Our primary outcome was the risk adjusted odds of 30 day readmission for all causes. We used the billing based variation of the Charlson comorbidity index as described by Deyo ${ }^{35}$ to adjust for differences across patients in risk factors for readmission; we did not use a commonly employed alternative risk adjustment method, the Elixhauser comorbidity adjustment scheme,${ }^{36}$ owing to the unavailability of Medicare disease related groups conversion codes for all of the study discharge records. Unlike the Agency for Health Care Quality state inpatient databases, the individual state databases we used do not contain discharge abstracts translated into a uniform format to facilitate multistate analyses. However, others have found that adjustment using the Charlson comorbidity index yields similar results to using other methods such as the Elixhauser risk adjustment scheme. $^{4}$

We analyzed overall readmission rates in each state, and then among several subgroups: the five most commonly occurring conditions at index discharge categorized by the Agency for Health Care Quality's clinical classifications software ${ }^{37}$; congestive heart failure and acute myocardial infarction (based on the Hospital Compare definition; Hospital Compare is a Medicare sponsored consumer oriented website that provides information on how well hospitals provide recommended care to their patients), ${ }^{38}$ and pneumonia; according to race/ethnicity, to assess for changes in the presence of disparities pre-reform and post-reform; and in counties with the highest baseline uninsurance rates versus counties with lower baseline uninsurance rates (analysis limited to the state of Massachusetts). We performed analyses comparing the primary outcome of readmission rates in Massachusetts versus control states (New York and New Jersey) and also compared Massachusetts to each control state separately. We also used a hierarchical logistic regression model (with the patient as the clustering unit) to account for the fact that patients might be included in the dataset multiple times.

\section{Analysis}

We performed an interrupted time series to examine pre-reform and post-reform trends, plotting readmission rates over time (quarter). We then used a difference in differences design to identify the post-reform change adjusted for secular changes unrelated to reform. ${ }^{39-41}$ This method is often used to estimate the impact of a policy (for example, health reform) on an outcome (for example, readmissions) by computing a double difference. One difference is over time (before-after) and the other is across subjects (between beneficiaries and non-beneficiaries). Because preintervention characteristics that may be associated with the outcome variable are likely to be unbalanced between groups it is necessary to control for these variables. Thus it is necessary to perform a logistic regression with interaction terms. ${ }^{42}$ Using the SAS computer statistical package, version 9.1 (SAS Institute, Cary, NC), we compared adults aged 18-64 in Massachusetts with adults aged 18-64 in the comparison states, and calculated the post-reform change associated with health reform as the odds ratio associated with the interaction of indicators for state (Massachusetts versus control states) and time period (pre-reform versus post-reform). To assess differences in disparities between states for the cohorts examined in this study, we performed logistic regression analysis that included a three way interaction between race/ethnicity, time (pre-reform versus post-reform), and state (Massachusetts versus New York and New Jersey, respectively; difference in difference in differences analysis).

For the analysis comparing counties in Massachusetts with high versus low baseline uninsurance rates, we performed logistic regression analysis that included a three way interaction between race/ethnicity, time (pre-reform versus post-reform), and county type (high versus low baseline uninsurance). We also performed a stratified analysis by race/ethnicity. All analyses adjusted for the effects of patient factors known to affect risk of readmission, including age, sex, and comorbidity. ${ }^{4} \mathrm{We}$ adjusted for hospital characteristics that changed differentially in the pre-reform and post-reform periods in Massachusetts versus control states. For example, the percentage of admissions that occurred in a teaching hospital decreased from $47.3 \%$ to $46.9 \%$ in Massachusetts, yet rose from $41.4 \%$ to $45.1 \%$ in control states. These characteristics included hospital ownership, teaching hospital status, and nurse to census ratio.

\section{Results}

Approximately 400000 index admissions took place in Massachusetts in the pre-reform and post-reform periods, respectively, and about 1.9 million index admissions in the control states (table $1 \Downarrow$ ). Patients in all states had a mean age of 46, yet patients in control states were more likely to be non-white and have a lower income compared with Massachusetts. The five most common conditions at index discharge were mood disorders or psychoses, back problems, chest pain or coronary artery disease, substance use disorders, and skin infections. Figure $1 \Downarrow$ shows that readmission rates over time were similar in Massachusetts versus control states, both in the overall population and among racial and ethnic subgroups. Approximately $14 \%$ of patients in all states were readmitted to hospital, in both the pre-reform (320 759/2 256103 patients) and post-reform (333 297/2 325062 patients) periods (table $2 \Downarrow)$. The adjusted odds of all cause readmission in Massachusetts 
compared with control states after health reform was 1.02 (95\% confidence interval 1.01 to $1.04, \mathrm{P}<0.05)$. In two separate analyses comparing Massachusetts with New Jersey and with New York, our findings were similar to our main analysis (adjusted odds of all cause readmission in Massachusetts compared with New Jersey 1.01 (95\% confidence interval 1.00 to $1.03, \mathrm{P}=0.10$ ); adjusted odds of all cause readmission in Massachusetts compared with New York 1.03 (1.01 to 1.04, $\mathrm{P}<0.01$; see supplementary appendix tables 1 and 2 ). In the hierarchical logistic regression model, the change in readmission rate associated with Massachusetts health reform went from $2.4 \%$ or an odds ratio of 1.02 without adjusting for clustering to $1.9 \%$ or an odds ratio of 1.02 adjusting for clustering. Both estimates were significant at the $\mathrm{P}=0.001$ and $\mathrm{P}=0.02$ levels, respectively. Since the results that did not adjust for clustering are similar to the results of the hierarchical logistic regression model that adjusted for clustering, we present the former results here.

Compared with control states, readmissions for mood disorders or psychoses fell in Massachusetts after health reform (adjusted odds ratio $0.91,95 \%$ confidence interval 0.86 to 0.95 ), while readmissions for substance use disorders $(1.07,1.03$ to 1.13$)$ and chest pain or coronary artery disease $(1.15,1.07$ to 1.23$)$ rose. There was no significant change in readmission rates in Massachusetts compared with the control states for congestive heart failure, acute myocardial infarction, or pneumonia (fig $2 \Downarrow)$.

Table $3 \Downarrow$ shows that Hispanic and black people in Massachusetts did not experience an improvement in readmission rates compared with Hispanic and black people in the control states. Further, racial and ethnic disparities (black-white and Hispanic-white) in all cause readmission rates did not change in Massachusetts compared with control states. Finally, there was a minimal overall difference in the change in readmission rates in Massachusetts counties with the highest baseline uninsurance rates versus other counties with lower baseline uninsurance rates (table $4 \Downarrow$ ). Black people in counties with the highest baseline uninsurance had a significantly decreased odds of readmission (adjusted odds ratio $0.91,95 \%$ confidence interval 0.84 to $1.00, \mathrm{P}<0.05$ ) compared with black people in counties with lower uninsurance. Similarly, white people in counties with the highest baseline uninsurance had a significantly decreased odds of readmission $(0.96,0.94$ to 1.00 , $\mathrm{P}<0.05)$ compared with white people in counties with lower uninsurance. The interaction term between black people and white people was not significant. Owing to multiple hypothesis testing, these findings should be interpreted cautiously.

\section{Discussion}

Following the implementation of health reform, Massachusetts residents aged 18-64 experienced a slight increased adjusted risk of 30 day readmissions, compared with similarly aged people in New York and New Jersey. For black and Hispanic people, the odds of readmission did not decrease in Massachusetts compared with control states, and there was no change in the magnitude of the white-black and white-Hispanic difference in readmission rates. Thus, in this outcome the presence of racial or ethnic disparities did not change, despite a noticeably higher baseline uninsurance rate in Massachusetts among Hispanic and black people. There were minimal overall differences in changes for Massachusetts readmission rates between counties with differing baseline uninsurance rates, but black people in counties with the highest baseline uninsurance had decreased odds of readmission compared with black people in counties with lower baseline uninsurance rates.

\section{Strengths and limitations of this study}

Our study has several limitations. We did not have data on utilization of outpatient care and thus cannot determine whether a lack of access to follow-up care prevented readmissions from improving in Massachusetts. We also did not have data on individual patients' insurance status prior to and subsequent to reform, because such all payer data did not exist in Massachusetts over the period spanning the reform. Finally, we did not have data on diagnosis related group codes, precluding adjustment for diagnosis related group weight, which is a separate construct (albeit related) from comorbidity. Other unmeasured factors may influence readmission rates, such as initiatives affecting transitions of care and underlying admission rates in the different states. Our data compare the changes in Massachusetts with changes in two mid-Atlantic states and not with other New England states or other states matched with Massachusetts on features such as baseline uninsurance rates. A strength of our study is that it is the first of which we are aware to examine the impact of extending health insurance coverage on 30 day readmissions - a current major policy focus-using data on actual (versus self reported) use of care.

\section{Comparison with other studies}

Our proposed mechanism linking health reform to reduced readmissions is predicated on the assumption that previously uninsured people, having gained insurance, would access outpatient follow-up care after hospital admission, thus averting readmission. Yet, in analyses of the behavioral risk factor surveillance survey, ${ }^{43}$ Zhu and colleagues found that in Massachusetts there were no improvements in accessing a personal doctor after reform (with approximately $9 \%$ of Massachusetts residents lacking a personal doctor). The inability to access a personal doctor in Massachusetts may be due to the shortage of primary care physicians, which has been well documented since 2006. ${ }^{44}$ Other studies in Massachusetts ${ }^{45} 46$ have also shown that access to care improved less than access to insurance, as many newly insured residents who obtained Medicaid or state subsidized private insurance still reported cost related access barriers. In addition to persistent financial barriers to accessing care (for example, high co-pays, premiums, deductibles, and uncovered services) for those with insurance gained under the reform, many providers do not accept these public forms of insurance because of low reimbursement rates. In 2010 , only $53 \%, 43 \%$, and $35 \%$ of Massachusetts providers accepted patients with Medicaid (Masshealth), Commonwealth Care, and Commonwealth Choice, respectively. ${ }^{47} 3$

Another potential explanation for our finding of a slight increase in readmissions after Massachusetts health reform is that gaining insurance may have enabled people to seek medical attention after a hospital admission. Such medical care may have uncovered medical problems requiring readmission. Weinberger and colleagues ${ }^{48}$ in a study of US veterans, found that an intervention that increased access to primary care after hospital discharge produced an increased rate of readmissions to hospital. Further, many of the newly insured in Massachusetts gained Medicaid coverage. Hasan and colleagues ${ }^{3}$ have shown that compared to those with private insurance, those with Medicaid also have an increased risk of readmission.

Readmissions also reflect the socioeconomic and health status ${ }^{49}$ of patients, with the sickest and most socioeconomically disadvantaged patients at highest risk for readmission. 
Multiple factors, including lack of social support, limited education, economic instability, limited access to care, and safety problems in the patient's environment have been shown to contribute to the risk of readmission. ${ }^{50}$ Receipt of insurance has not been shown to improve health status in Massachusetts, ${ }^{43}$ and since there were no major improvements in socioeconomic status during the period of Massachusetts health reform (indeed, the reform was concomitant with an economic downturn), it is perhaps not surprising that we did not observe a change in readmissions. Improvement in 30 day readmissions also requires changes in healthcare delivery, including greater focus on discharge planning and access to primary care. Moreover, 30 day readmissions may be driven largely by regional variations in underlying admission rates, ${ }^{32}$ which are likely to be unaffected by an insurance expansion. The people in Massachusetts who primarily gained health insurance may have been young and healthy and therefore not at high risk for hospital admissions and subsequent readmissions. In addition, many of the previously uninsured people may have been covered by Free Care, the Massachusetts uncompensated care pool. Thus they were not truly uninsured prior to reform because they were able to access care through this program. Finally, Massachusetts health reform - which only dealt with payment mechanisms rather than the organization of care-had no impact on the increasing fragmentation of patient care and lack of coordinated care transitions ${ }^{51}$ that may also perpetuate high readmission rates.

\section{Conclusions and policy implications}

We have shown that in a state with a low baseline uninsurance rate, a health insurance expansion was not associated with a significant reduction in 30 day readmissions, but rather a slight increase. Future studies might explore whether expanding health insurance coverage to states with uninsurance rates twice and three times as high might affect readmissions, as will occur with implementation of the Affordable Care Act. Our findings suggest that to reduce readmissions and disparities in readmissions, states like Massachusetts need to go beyond simply expanding insurance coverage. Further intervention studies are needed; such interventions might reduce financial access barriers, increase reimbursement rates for new insurance plans, implement medication reconciliation and patient coaching, ${ }^{52}$ improve disease management and coordination of care, and provide hospital based incentives to reduce use of inpatient services. Interventions could also tackle the shortage of primary care providers. Finally, though expanding insurance may not lead to a reduction in 30 day readmissions, the association of uninsurance with mortality ${ }^{53}$ makes the expansion of insurance coverage to all a moral imperative.

We thank Maxim D Shrayer and Ashish Jha who commented on earlier drafts of the manuscript, and Lisa Marks who assisted with preparation of the manuscript.

Contributors: All authors contributed to the data analysis and interpretation of the results, and reviewed and approved the final manuscript. KEL had full access to all of the data in the study and takes responsibility for the integrity of the data and the accuracy of the data analysis. She is guarantor.

Funding: This research has been funded by US National Institutes of Health grants (1R21NS062677, ADH, principal investigator, and 1U01HL105342-01, NRK, principal investigator) and a grant from the $\mathrm{Rx}$ foundation. NRK is supported in part by a senior research career scientist award from the Department of Veterans Affairs, Health Services Research and Development Service (RCS 02-066-1). The views expressed in this article are those of the authors and do not necessarily represent the views of the National Institutes of Health, the $R x$ foundation, Boston University, or the Department of Veterans Affairs.

Competing interests: All authors have completed the ICMJE uniform disclosure form at www.icmje.org/coi_disclosure.pdf and declare: no support from any organisation for the submitted work; no financial relationships with any organisations that might have an interest in the submitted work in the previous three years; no other relationships or activities that could appear to have influenced the submitted work.

Ethical approval: This study was approved by the Boston University Medical Campus institutional review board.

Data sharing: Inpatient data files were restricted for this project and cannot be shared because of restrictions on use of data. Statistical code files are available from the corresponding author

(karen.lasser@bmc.org).

Transparency: The lead author, KEL (the manuscript's guarantor), affirms that the manuscript is an honest, accurate, and transparent account of the study being reported; that no important aspects of the study have been omitted; and that any discrepancies from the study as planned (and, if relevant, registered) have been explained.

1 Jencks SF, Williams MV, Coleman EA. Rehospitalizations among patients in the Medicare fee-for-service program. N Engl J Med 2009;360:1418-28.

2 CMS.gov. Readmissions reduction program 2013. www.cms.gov/Medicare/Medicare-Feefor-Service-Payment/AcutelnpatientPPS/Readmissions-Reduction-Program.html.

3 Hasan O, Meltzer DO, Shaykevich SA, Bell CM, Kaboli PJ, Auerbach AD, et al. Hospital readmission in general medicine patients: a prediction model. J Gen Intern Med 2010;25:211-9.

4 Joynt KE, Orav EJ, Jha AK. Thirty-day readmission rates for Medicare beneficiaries by race and site of care. JAMA 2011;305:675-81.

5 Ayanian JZ, Weissman JS, Schneider EC, Ginsburg JA, Zaslavsky AM. Unmet health needs of uninsured adults in the United States. JAMA 2000;284:2061-9.

6 Ayanian JZ, Kohler BA, Abe T, Epstein AM. The relation between health insurance coverage and clinical outcomes among women with breast cancer. $N$ Engl $\mathrm{J} \mathrm{Med}$ 1993;329:326-31.

7 Baker DW, Sudano JJ, Albert JM, Borawski EA, Dor A. Lack of health insurance and decline in overall health in late middle age. N Engl J Med 2001;345:1106-12.

8 Baker DW, Sudano JJ, Albert JM, Borawski EA, Dor A. Loss of health insurance and the risk for a decline in self-reported health and physical functioning. Med Care 2002;40:1126-31.

9 Brook RH, Ware JE Jr, Rogers WH, Keeler EB, Davies AR, Donald CA, et al. Does free care improve adults' health? Results from a randomized controlled trial. $N$ Engl J Med 1983;309:1426-34.

10 Committee on the Consequences of Uninsurance, Board on Health Care Services loM. Care without coverage: too little, too late. National Academy Press, 2002.

11 DeVoe JE, Fryer GE, Phillips R, Green L. Receipt of preventive care among adults: insurance status and usual source of care. Am J Public Health 2003;93:786-91.

12 Franks P, Clancy CM, Gold MR, Nutting PA. Health insurance and subjective health status: data from the 1987 National Medical Expenditure survey. Am J Public Health 1993;83:1295-9.

13 Freeman JD, Kadiyala S, Bell JF, Martin DP. The causal effect of health insurance on utilization and outcomes in adults: a systematic review of US studies. Med Care 2008;46:1023-32.

14 Hernandez AF, Greiner MA, Fonarow GC, Hammill BG, Heidenreich PA, Yancy CW, et al. Relationship between early physician follow-up and 30-day readmission among Medicare beneficiaries hospitalized for heart failure. JAMA 2010;303:1716-22.

15 Franks P, Clancy CM, Gold MR. Health insurance and mortality. Evidence from a national cohort. JAMA 1993;270:737-41.

16 Andrulis DP. Access to care is the centerpiece in the elimination of socioeconomic disparities in health. Ann Intern Med 1998;129:412-6.

17 Long SK, Masi PB. Access and affordability: an update on health reform in Massachusetts, fall 2008. Health Aff (Millwood) 2009;28:w578-87.

18 Mass.gov. Health care reform: general information. www.mass.gov/dor/individuals/taxpayerhelp-and-resources/health-care-reform-information/general-information-for-individuals. html.

19 Long SK, Stockley K. The impacts of state health reform initiatives on adults in New York and Massachusetts. Health Serv Res 2011:46:365-87.

20 kff.org. State marketplace profiles: Massachusetts. kff.org/health-reform/state-profile/stateexchange-profiles-massachusetts/.

21 Mass.gov. Minimum creditable coverage. www.mass.gov/chia/gov/commissions-andinitiatives/minimum-creditable-coverage.html.

22 McDonough JE, Rosman B, Butt M, Tucker L, Howe LK. Massachusetts health reform implementation: major progress and future challenges. Health Aff (Millwood) 2008;27:w285-97.

23 Centers for Disease Control. Behavioral risk factor surveillance system: 2009 summary data quality report. CDC, 2011.

24 Centers for Disease Control. Behavioral risk factor surveillance system: 2006 summary data quality report. CDC, 2007.

25 Cook A, Holahan J. Health insurance coverage and the uninsured in Massachusetts: an update based on 2005 current population survey data. The Urban Institute, 2007.

26 kff.org. Massachusetts health care reform: six years later. kaiserfamilyfoundation.files. wordpress.com/2013/01/8311.pdf.

27 kff.org. Summary of the affordable care act. kaiserfamilyfoundation.files.wordpress.com/ 2011/04/8061-021.pdf.

28 HealthCare.gov. Essential health benefits. www.healthcare.gov/glossary/essential-healthbenefits/. 


\section{What is already known on this topic}

Uninsured people and minority groups are at increased risk for 30 day hospital readmissions

It is unknown whether expanding health insurance coverage can reduce the risk of readmissions in the overall population, specifically among minority populations

It is also unknown whether an insurance expansion might have differential effects related to variation in baseline uninsurance rates

\section{What this study adds}

Extending health insurance coverage alone seems insufficient to improve readmission rates at the population level

To reduce readmissions and disparities in readmissions, states in the United States such as Massachusetts need to go beyond simply expanding insurance coverage

29 MA Division of Health Care Finance and Policy. FY2007 Inpatient Hospital Discharge Database documentation manual. Division of Health Care Finance and Policy, Massachusetts Executive Office of Health and Human Services, 2009.

30 Hyams T, Cohen L. Massachusetts health reform: impact on women's health. masshealthpolicyforum.brandeis.edu/forums/Documents/Issue\%20Brief_ConnorCenter. pdf.

31 Joynt KE, Orav EJ, Jha AK. The association between hospital volume and processes, outcomes, and costs of care for congestive heart failure. Ann Intern Med 2011:154:94-102.

32 Epstein AM, Jha AK, Orav EJ. The relationship between hospital admission rates and rehospitalizations. N Engl J Med 2011;365:2287-95.

33 Werner RM, Goldman LE, Dudley RA. Comparison of change in quality of care between safety-net and non-safety-net hospitals. JAMA 2008;299:2180-7.

34 National Conference of State Legislatures. Health reform: state examples: www.ncsl.org/ research/health/state-examples-pre-federal-health-reform.aspx.

35 Deyo RA, Cherkin DC, Ciol MA. Adapting a clinical comorbidity index for use with ICD-9-CM administrative databases. J Clin Epidemiol 1992;45:613-9.

36 Elixhauser A, Steiner C, Harris DR, Coffey RM. Comorbidity measures for use with administrative data. Med Care 1998;36:8-27.

37 Healthcare Cost and Utilization Project. Clinical Classifications Software (CCS) for ICD-9-CM. www.hcup-us.ahrq.gov/toolssoftware/ccs/ccs.jsp.

38 Medicare.gov. 30-day death and readmission measures data. www.medicare.gov/ hospitalcompare/data/rcd/30-day-measures.aspx?AspxAutoDetectCookieSupport=1.

39 Joynt K, Blumenthal D, Orav E, Resnic F, Jha A. Association of public reporting for percutaneous coronary intervention with utilization and outcomes among Medicare beneficiaries with acute myocardial infarction. JAMA 2012;308:1460-8.

40 Hanchate A, Lasser K, Kapoor A, Rosen J, McCormick D, D'Amore M, et al. Massachusetts reform and disparities in inpatient care utilization. Med Care 2012;50:569-77.

41 Sommers B, Baicker K, Epstein A. Mortality and access to care among adults after state Medicaid expansions. N Engl J Med 2012;367:1025-34.

42 Abadie A. Semiparametric difference-in-differences estimators. Rev Econ Stud 2005;72:1-19.

43 Zhu J, Brawarsky P, Lipsitz S, Huskamp H, Haas JS. Massachusetts health reform and disparities in coverage, access and health status. J Gen Intern Med 2010;25:1356-62.

44 Massachusetts Medical Society. Massachusetts Medical Society's 2013 Physician Workforce Study shows physician shortages, difficulty in recruiting. www.massmed.org/
News-and-Publications/MMS-News-Releases/Massachusetts-Medical-Society's-2013Physician-Workforce-Study-Shows-Physician-Shortages,-Difficulty-in-Recruiting/. 45 McCormick D, Sayah A, Lokko H, Woolhandler S, Nardin R. Access to care after Massachusetts' health care reform: a safety net hospital patient survey. J Gen Intern Med 2012;27:1548-54

46 Galbraith AA, Sinaiko AD, Soumerai SB, Ross-Degnan D, Dutta-Linn MM, Lieu TA. Some families who purchased health coverage through the Massachusetts connector wound up with high financial burdens. Health Aff 2013;32:974-83.

47 QualityNet. Readmission measures overview. Publicly reporting risk-standardized, 30-day readmission measures for AMI, HF, and PN. 2012 www.qualitynet.org/dcs/ContentServer? pagename $=$ QnetPublic\%2FPage\%2FQnetTier3\&cid $=1219069855273$.

48 Weinberger M, Oddone EZ, Henderson WG. Does increased access to primary care reduce hospital readmissions? Veterans Affairs Cooperative Study Group on Primary Care and Hospital Readmission. N Engl J Med 1996;334:1441-7.

49 Joynt KE, Jha AK. A path forward on Medicare readmissions. N Engl J Med 2013;368:1175-7.

50 Hersh AM, Masoudi FA, Allen LA. Postdischarge environment following heart failure hospitalization: expanding the view of hospital readmission. JAHA 2013;2:e000116.

51 Williams MV. A requirement to reduce readmissions: take care of the patient, not just the disease. JAMA 2013:309:394-6.

52 Burke RE Kripalani S, Vasilevskis EE, Schnipper JL. Moving beyond readmission penalties: creating an ideal process to improve transitional care. J Hosp Med 2013;8:102-9.

53 Wilper AP, Woolhandler, Lasser KE, McCormick D, Bor DH, Himmelstein DU. Health insurance and mortality in US adults. Am J Public Health 2009;99:2289-95.

\section{Accepted: 17 March 2014}

\section{Cite this as: BMJ 2014;348:g2329}

This is an Open Access article distributed in accordance with the Creative Commons Attribution Non Commercial (CC BY-NC 3.0) license, which permits others to distribute, remix, adapt, build upon this work non-commercially, and license their derivative works on different terms, provided the original work is properly cited and the use is non-commercial. See: http://creativecommons.org/licenses/by-nc/3.0/. 


\section{Tables}

Table 1/ Patient and hospital characteristics of 30 day readmissions for all causes in Massachusetts compared with control states (New York and New Jersey), 2004-09, aged 18-64. Values are percentages (numbers) unless stated otherwise

\begin{tabular}{|c|c|c|c|c|}
\hline \multirow[t]{2}{*}{ Characteristics } & \multicolumn{2}{|c|}{ Pre-reform* } & \multicolumn{2}{|c|}{ Post-reform* } \\
\hline & Massachusetts & Control states & Massachusetts & Control states \\
\hline No of index admissions & 392517 & 1863586 & 406383 & 1918679 \\
\hline \multicolumn{5}{|l|}{ Patients } \\
\hline Mean (SD) age (years) & $46.4(12.2)$ & $46.4(11.8)$ & $46.9(12.3)$ & $46.5(12.2)$ \\
\hline Female sex & $51.0(200343)$ & $50.8(945741)$ & $51.0(207367)$ & 50.5 (969 579) \\
\hline \multicolumn{5}{|l|}{ Race/ethnicity: } \\
\hline Non-Hispanic black & $8.3(32$ 709) & $21.9(408936)$ & $9.0(36727)$ & $21.7(416818)$ \\
\hline Hispanic & $7.5(29497)$ & $14.3(266825)$ & $8.5(34487)$ & $14.6(280844)$ \\
\hline Other & $4.1(15978)$ & $7.0(130782)$ & $3.5(14035)$ & $7.0(149895)$ \\
\hline Non-Hispanic white & 80.1 (314 333) & 56.7 (1 057043$)$ & $79.0(321134)$ & $56.7\left(\begin{array}{llllllll}1 & 071 & 122\end{array}\right)$ \\
\hline \multicolumn{5}{|l|}{ Incomet: } \\
\hline$<\$ 50000$ & $53.2(208940)$ & $60.9\left(\begin{array}{llll}1 & 135 & 364\end{array}\right)$ & $53.6(217919)$ & 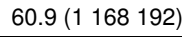 \\
\hline \multicolumn{5}{|l|}{$\begin{array}{l}\text { Top } 5 \text { primary admitting } \\
\text { diagnosesł: }\end{array}$} \\
\hline $\begin{array}{l}\text { Mood disorders, schizophrenia, } \\
\text { and other psychotic disorders }\end{array}$ & $7.7(30180)$ & $7.5(139930)$ & $8.1(32915)$ & $7.5(144729)$ \\
\hline Back problems and osteoporosis & $6.0(23427)$ & $4.4(81915)$ & $6.5(26284)$ & $4.6(87833)$ \\
\hline $\begin{array}{l}\text { Non-specified chest pain and } \\
\text { coronary atherosclerosis }\end{array}$ & $5.6(22153)$ & $9.1(168808)$ & $3.9(15918)$ & $7.8(150312)$ \\
\hline $\begin{array}{l}\text { Substance related and alcohol } \\
\text { related disorders }\end{array}$ & $5.1(20105)$ & $6.1(113887)$ & $4.7(19$ 191) & $5.6(107318)$ \\
\hline $\begin{array}{l}\text { Skin and subcutaneous tissue } \\
\text { infections }\end{array}$ & $2.4(9564)$ & $2.3(43647)$ & $2.7(11124)$ & $2.7(51710)$ \\
\hline \multicolumn{5}{|l|}{ Selected conditions admissions: } \\
\hline Acute myocardial infarction§ & $1.7(6588)$ & $1.4(25742)$ & $1.5(6068)$ & $1.4(25930)$ \\
\hline Congestive heart failure & $1.3(4982)$ & $1.7(31515)$ & $1.2(4918)$ & $1.5(28901)$ \\
\hline Pneumoniał & $2.5(9856)$ & $2.1(38813)$ & $2.4(9694)$ & $2.0(37854)$ \\
\hline \multicolumn{5}{|l|}{ Charlson score: } \\
\hline 0 & $58.0(227837)$ & $60.5\left(\begin{array}{l}1 \\
127\end{array} 834\right)$ & $55.1(223892)$ & 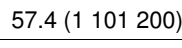 \\
\hline $1-2$ & $31.7(124307)$ & $30.5(568404)$ & $32.8(133273)$ & $31.7(607660)$ \\
\hline $3-4$ & 5.7 (22 192) & $5.2(97572)$ & $6.9(28033)$ & $6.6(126896)$ \\
\hline$>4$ & $4.6(18181)$ & 3.7 (69 776) & $5.2(21185)$ & $4.3(82923)$ \\
\hline $\begin{array}{l}\text { Median (interquartile range) length } \\
\text { of stay (days) }\end{array}$ & $3.0(3.0)$ & $3.0(4.0)$ & $3.0(3.0)$ & $3.0(3.0)$ \\
\hline \multicolumn{5}{|l|}{ Hospitals } \\
\hline$<400$ beds & $59.8(234564)$ & $48.5(903067)$ & $57.2(232294)$ & $45.1(865278)$ \\
\hline Missing & $0.24(942)$ & $0.97(18$ 107) & 1.89 (7670) & 2.58 (49 587) \\
\hline \multicolumn{5}{|l|}{ Type of ownership: } \\
\hline For profit & $5.4(21027)$ & $0.5(8512)$ & $3.8(15593)$ & $0.5(9991)$ \\
\hline Public & $3.9(15289)$ & $12.8(237621)$ & $2.1(8575)$ & $14.3(274372)$ \\
\hline Private non-profit & 90.5 (355 259) & 85.8 (1 599346$)$ & $92.2(374545)$ & $82.6(1584729)$ \\
\hline Missing & $0.24(942)$ & $0.97(18$ 107) & $1.89(7670)$ & $2.58(49587)$ \\
\hline Teaching hospital & $47.3(185722)$ & 41.4 (771 265) & $46.9(190672)$ & 40.9 (783 996) \\
\hline Missing & $0.24(942)$ & $0.97(18107)$ & $1.89(7670)$ & $2.58(49587)$ \\
\hline Safety net hospitalq & 30.4 (119 339) & 28.6 (532 592) & 29.4 (119 389) & $27.3(522$ 825) \\
\hline \multicolumn{5}{|l|}{ Nurse to census ratio: } \\
\hline Per 1000 patient days $s^{\star \star}$ & $36.5(143206)$ & $46.8(872216)$ & $46.8(190351)$ & $53.6\left(\begin{array}{l}1 \\
027\end{array} 921\right)$ \\
\hline
\end{tabular}




\section{Table 1 (continued)}

\begin{tabular}{lcccc} 
Characteristics & \multicolumn{2}{c}{ Pre-reform* $^{*}$} & \multicolumn{2}{c}{ Post-reform* $^{*}$} \\
\cline { 2 - 3 } Missing & Massachusetts & Control states & Massachusetts & Control states \\
\hline
\end{tabular}

$\$ 1.00$ (£0.60; €0.72).

*Pre-reform period defined as 1 September 2004 to 30 June 2006; post-reform period defined as 1 January 2008 to 30 September 2009.

†Based on zip code median level income.

$\ddagger$ Patient diagnoses categorized by AHRQ’s Clinical Classifications Software (CCS).

§Patient diagnoses categorized by Medicare's Hospital Compare definition for readmissions.

ףHospitals caring for first quarter of highest volume of patients insured by Medicaid, free care, self-pay, and Commonwealth care; the classification is based on

2004-09 inpatient discharge data.

${ }^{\star *}$ Calculated by dividing the number of nurses on staff by the number of patient days in thousands. 
Table 2| Changes in 30 day readmission rates in Massachusetts (MA) and control states (New Jersey and New York) after healthcare reform, ages 18-64

\begin{tabular}{|c|c|c|c|c|c|c|c|c|c|}
\hline \multirow[b]{2}{*}{$\begin{array}{l}\text { Index admission } \\
\text { diagnosis }\end{array}$} & \multicolumn{3}{|c|}{ Unadjusted readmission rates (\%): MA } & \multicolumn{3}{|c|}{$\begin{array}{l}\text { Unadjusted readmission rates (\%): control } \\
\text { states }\end{array}$} & \multirow{2}{*}{$\begin{array}{c}\text { Difference } \\
\text { in } \\
\text { differences } \\
\text { (\%)§: MA } v \\
\text { control }\end{array}$} & \multirow{2}{*}{$\begin{array}{c}\text { Adjusted odds } \\
\text { ratio }(95 \% \mathrm{Cl}) \ddagger \\
\text { of } 30 \text { day all } \\
\text { cause } \\
\text { readmission: } \\
\text { MA } v \text { control } \\
\text { states }\end{array}$} & \multirow[b]{2}{*}{$P$ value } \\
\hline & Pre-reform* & Post-reform & $\begin{array}{c}\text { Change } \\
(\%)\end{array}$ & Pre-reform ${ }^{\star}$ & Post-reform & $\begin{array}{c}\text { Change } \\
(\%)\end{array}$ & & & \\
\hline $\begin{array}{l}\text { All diagnoses, } \\
\text { excluding obstetrical }\end{array}$ & $\begin{array}{c}14.3(55 \\
985 / 392521)\end{array}$ & $\begin{array}{c}14.5(58 \\
778 / 406388)\end{array}$ & 0.2 & $\begin{array}{l}14.2(267412 / 1 \\
890140)\end{array}$ & $\begin{array}{l}14.3(274365 / 1 \\
923313)\end{array}$ & 0.1 & 0.1 & $\begin{array}{l}1.02(1.01 \text { to } \\
1.04)\end{array}$ & 0.0011 \\
\hline \multicolumn{10}{|l|}{$\begin{array}{l}\text { Top five index } \\
\text { admission } \\
\text { diagnosest: }\end{array}$} \\
\hline $\begin{array}{l}\text { Mood disorders and } \\
\text { schizophrenia and } \\
\text { other psychotic } \\
\text { disorders }\end{array}$ & $\begin{array}{c}18.1(5453 / 30 \\
180)\end{array}$ & $\begin{array}{c}16.6(5462 / 32 \\
915)\end{array}$ & -1.5 & $\begin{array}{c}17.6(24685 / 139 \\
930)\end{array}$ & $\begin{array}{c}17.7(25571 / 144 \\
729)\end{array}$ & 0.0 & -1.5 & $\begin{array}{c}0.91(0.86 \text { to } \\
0.95)\end{array}$ & $<0.001$ \\
\hline $\begin{array}{l}\text { Back problems and } \\
\text { osteoporosis }\end{array}$ & $\begin{array}{c}8.2(1925 / 23 \\
427)\end{array}$ & $\begin{array}{c}6.8(1781 / 26 \\
284)\end{array}$ & -1.4 & $\begin{array}{c}12.2(9966 / 81 \\
915)\end{array}$ & $\begin{array}{c}11.0(9651 / 87 \\
833)\end{array}$ & -1.2 & -0.3 & $\begin{array}{c}0.93(0.87 \text { to } \\
1.01)\end{array}$ & 0.068 \\
\hline $\begin{array}{l}\text { Non-specified chest } \\
\text { pain and coronary } \\
\text { atherosclerosis }\end{array}$ & $\begin{array}{c}10.1(2231 / 22 \\
153)\end{array}$ & $\begin{array}{c}11.4(1811 / 15 \\
918)\end{array}$ & 1.3 & $\begin{array}{c}9.3(15638 / 168 \\
808)\end{array}$ & $\begin{array}{c}9.3(13929 / 150 \\
312)\end{array}$ & 0.0 & 1.3 & $\begin{array}{c}1.15(1.07 \text { to } \\
1.23)\end{array}$ & 0.0002 \\
\hline $\begin{array}{l}\text { Substance related } \\
\text { and alcohol related } \\
\text { disorders }\end{array}$ & $\begin{array}{c}14.5(2911 / 20 \\
105)\end{array}$ & $\begin{array}{c}15.8(3030 / 19 \\
191)\end{array}$ & 1.3 & $\begin{array}{c}22.6(25694 / 113 \\
887)\end{array}$ & $\begin{array}{c}22.1(23741 / 107 \\
318)\end{array}$ & -0.4 & 1.8 & $\begin{array}{c}1.07(1.03 \text { to } \\
1.13)\end{array}$ & 0.018 \\
\hline $\begin{array}{l}\text { Skin and } \\
\text { subcutaneous tissue } \\
\text { infections }\end{array}$ & $\begin{array}{c}11.3 \\
(1083 / 9564)\end{array}$ & $\begin{array}{c}10.7(1195 / 11 \\
124)\end{array}$ & -0.6 & $\begin{array}{c}9.7(4215 / 43 \\
647)\end{array}$ & $\begin{array}{c}9.3(4829 / 51 \\
710)\end{array}$ & -0.3 & -0.3 & $\begin{array}{c}1.00(0.90 \text { to } \\
1.10)\end{array}$ & 0.98 \\
\hline
\end{tabular}

*Pre-reform period defined as 1 September 2004 to 30 June 2006; post-reform period defined as 1 January 2008 to 30 September 2009.

†Patient diagnoses categorized by Agency for Health Care Quality's Clinical Classifications Software (CCS).

$\ddagger$ Adjusted for age, sex, comorbidity, hospital ownership, teaching hospital, and nurse to census ratio.

$\S$ Compared changes of pre-reform to post-reform between MA and control states where reference is control states; unadjusted. 
Table 3| Changes in 30 day readmission rates among all index admissions, aged 18-64, in Massachusetts (MA) and control states (New York and New Jersey) after healthcare reform, according to race/ethnicity

\begin{tabular}{|c|c|c|c|c|c|c|c|c|}
\hline \multirow[b]{2}{*}{ Race/ethnicity } & \multicolumn{2}{|c|}{ Readmission rate (\%): MA } & \multicolumn{2}{|c|}{ Readmission rate $(\%)$ : control states } & \multirow{2}{*}{$\begin{array}{c}\text { Odds ratio ( } 95 \% \\
\mathrm{Cl}) \text { of } 30 \text { day all } \\
\text { cause } \\
\text { readmission: MA } \\
v \text { control states, } \dagger \\
\text { stratified by race }\end{array}$} & \multirow{2}{*}{\multicolumn{2}{|c|}{$\begin{array}{l}\text { Odds ratio (95\% } \\
\text { Cl) change in } \\
\text { black-white and } \\
\text { Hispanic-white } \\
\text { differences in } \\
\text { readmission rates } \\
\text { in MA } v \text { control } \\
\text { states†‡ }\end{array}$}} & \multirow[b]{2}{*}{$P$ value } \\
\hline & Pre-reform* & Post-reform & Pre-reform* & $\begin{array}{l}\text { Post-reform } \\
\text { readmission rate }\end{array}$ & & & & \\
\hline White & $\begin{array}{c}14.3(44895 / 314 \\
336)\end{array}$ & $\begin{array}{c}14.4(46357 / 321 \\
138)\end{array}$ & $\begin{array}{c}13.8(145998 / 1 \\
057056)\end{array}$ & $\begin{array}{c}14.1(150960 / 1071 \\
136)\end{array}$ & 1.01 (0.99 to 1.02$)$ & 0.38 & Ref & \\
\hline Black & $\begin{array}{c}17.1(5586 / 32 \\
709)\end{array}$ & $\begin{array}{c}16.9(6199 / 36 \\
727)\end{array}$ & $\begin{array}{c}16.8(68550 / 408 \\
939)\end{array}$ & $\begin{array}{c}16.7(69742 / 416 \\
820)\end{array}$ & $1.00(0.96$ to 1.05$)$ & 0.86 & 1.01 (0.96 to 1.05$)$ & 0.76 \\
\hline Hispanic & $\begin{array}{c}14.3(4228 / 29 \\
497)\end{array}$ & $\begin{array}{c}14.3(4931 / 34 \\
487)\end{array}$ & $\begin{array}{c}14.5(38583 / 266 \\
825)\end{array}$ & $\begin{array}{c}14.1(39559 / 280 \\
846)\end{array}$ & 1.04 (0.99 to 1.09$)$ & 0.13 & $1.03(0.98$ to 1.09$)$ & 0.22 \\
\hline
\end{tabular}

*Pre-reform period defined as 1 September 2004 to 30 June 2006; post-reform period defined as 1 January 2008 to 30 September 2009. †Adjusted for age, sex, comorbidity, hospital ownership, teaching hospital, and nurse to census ratio.

$\ddagger T o$ assess differences in disparities between states, logistic regression analysis was performed and included three way interaction between race, time (pre-reform $v$ post-reform), and state (Massachusetts $v$ New York and New Jersey, respectively; difference in difference in differences analysis. 
Table 4| Changes in 30 day readmission rates among all index admissions, aged 18-64, in Massachusetts (MA) after healthcare reform, according to county level baseline uninsurance rate

\begin{tabular}{|c|c|c|c|c|c|c|}
\hline \multirow[t]{3}{*}{ Race/ethnicity } & \multirow{2}{*}{\multicolumn{2}{|c|}{$\begin{array}{l}\text { Readmission rate (\%): MA counties with } \\
\text { high uninsurance }{ }^{\star} \text { pre-reform }\end{array}$}} & \multirow{2}{*}{\multicolumn{2}{|c|}{$\begin{array}{l}\text { Readmission rate }(\%) \text { : MA counties with } \\
\text { low uninsurance* pre-reform }\end{array}$}} & \multicolumn{2}{|c|}{ Odds ratio $(95 \% \mathrm{Cl})$} \\
\hline & & & & & \multirow{2}{*}{$\begin{array}{c}30 \text { day all cause } \\
\text { readmission in high } \\
v \text { low uninsurance } \\
\text { counties } †\end{array}$} & \multirow[b]{2}{*}{$\begin{array}{l}\text { Change in black-white } \\
\text { and Hispanic-white } \\
\text { differences in } \\
\text { readmission rates in } \\
\text { MA high } v \text { low } \\
\text { uninsurance } \\
\text { counties } † \neq\end{array}$} \\
\hline & Pre-reform§ & Post-reform & Pre-reform§ & Post-reform & & \\
\hline Total & $14.2(27049 / 190312)$ & 14.3 (28 103/196 899) & $14.3(28932 / 202$ 185) & $14.6(30675 / 209484)$ & $0.96(0.94$ to 0.99$) \uparrow$ & - \\
\hline White & $14.2(20$ 469/144 657) & $14.2(20768 / 146510)$ & $14.4(24$ 422/169 656) & $14.7(25$ 589/174 623) & $0.96(0.94$ to 0.99$) \uparrow$ & Ref \\
\hline Black & $17.8(3687 / 20733)$ & $17.1(3978 / 23308)$ & $15.9(1899 / 11975)$ & $16.6(2221 / 13419)$ & $0.91(0.84$ to 1.00$) \uparrow$ & $0.93(0.85$ to 1.01$)$ \\
\hline Hispanic & $13.7(2097 / 15350)$ & $13.7(2582 / 18810)$ & $15.1(2131 / 14147)$ & $15.0(2349 / 15677)$ & $1.00(0.91$ to 1.10$)$ & $1.04(0.94$ to 1.14$)$ \\
\hline
\end{tabular}

${ }^{*}$ Counties are dichotomized based on their uninsurance rate with two counties of small population merged into adjacent ones generating a total of 11 counties in MA.

†Adjusted for age, sex, comorbidity, hospital ownership, teaching hospital, and nurse to census ratio.

$\ddagger$ To assess differences in disparities between counties, logistic regression analysis was performed and included three way interaction between race, time (pre-reform $v$ post-reform), and county type (high $v$ low uninsurance pre-reform); difference in difference in differences analysis.

§Pre-reform period defined as 1 September 2004 to 30 June 2006; post-reform period defined as 1 January 2008 to 30 September 2009.

$\mathbb{\Uparrow P}<0.05$. 


\section{Figures}
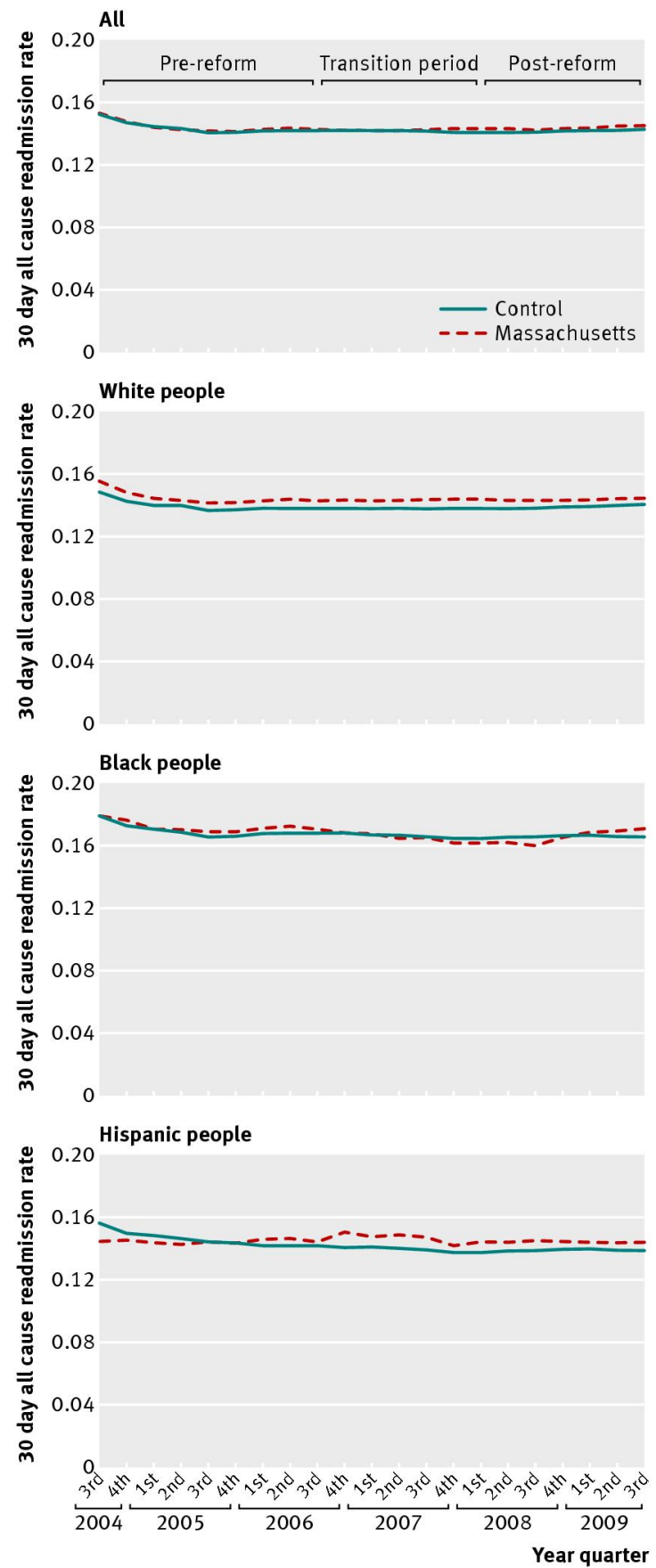

Fig 1 Quarterly readmission rate in Massachusetts versus control states (New York and New Jersey) overall and by race/ethnicity, among patients aged 18-64 


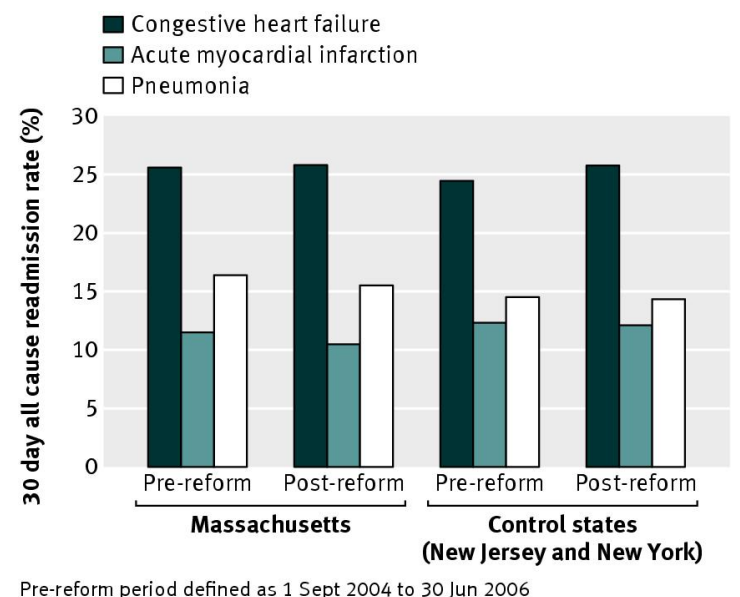

Post-reform period defined as 1 Jan 2008 to 30 Sept 2009

Fig 2 Changes in 30 day readmission rates for congestive heart failure, myocardial infarction, and pneumonia in Massachusetts versus control states (New York and New Jersey) after healthcare reform, among patients aged 18-64 